\title{
Jogos matemáticos como recurso didático no ensino da subtração: o discurso docente ${ }^{1}$
}

\author{
Emanuela Galvão Páscoa ${ }^{2}$ \\ Mara Silvana Ferreira Godinho ${ }^{3}$ \\ Francisco Marcôncio Targino de Moura ${ }^{4}$
}

\section{Resumo}

Nosso objetivo, nessa pesquisa, foi investigar que contribuições os professores atribuem aos jogos matemáticos como recurso didático para superação de dificuldades no trabalho pedagógico da subtração. A pesquisa foi realizada tendo uma abordagem qualitativa, onde escolhemos como método a pesquisa exploratória. Para a coleta de dados trabalhamos com documentos e entrevistas. As possibilidades com os jogos, demonstradas dentro da pesquisa, foram inúmeras, desde a construção de conceitos a conhecimentos anteriores ao entendimento propriamente dito da subtração. Essa relação vai desde a possibilidade do jogo como estratégia para o conhecimento matemático à prática e disponibilidade do professor, visando a possibilidade de um trabalho fundamentado e integrativo entre professores e alunos.

Palavras-chave: Jogos Matemáticos; Subtração; Prática Pedagógica.

Mathematic games as a teaching resource in teaching subtraction: the teacher speech

\section{Abstract}

Our objective in this research was to investigate what contributions teachers attribute to mathematical games as a didactic resource to overcome difficulties in the pedagogical work of subtraction. The research was carried out taking a qualitative approach, where we chose as exploratory research method. For data collection we work with documents and interviews. The possibilities with games, demonstrated within the research, were numerous, from the construction of concepts to knowledge prior to the proper understanding of subtraction. This relationship goes from the possibility of the game as a strategy for mathematical knowledge to the practice and availability of the teacher, aiming at the possibility of a grounded and integrative work between teachers and students. Keywords: Mathematical Games; Subtraction; Pedagogical Practice.

\section{Introdução}

O jogo é uma das atividades lúdicas utilizadas pela humanidade desde tempos remotos. A presença dessa atividade para a humanidade se configura como parte importante do desenvolvimento, que está ligada à cultura e à identidade de todos os povos.

\footnotetext{
${ }^{1}$ Texto resultante da apresentação de um painel no XVIII Encontro Nacional de Didática e Prática de Ensino -ENDIPE ocorrido em Cuiabá-MT em 2016.

2 Escolinha Primeiro Mundo, Fortaleza/CE, emanuelapascoa@hotmail.com

${ }^{3}$ Colégio Santa Cecília, Fortaleza/CE, marasfgodinho@gmail.com

${ }^{4}$ Secretaria Municipal de Educação de Fortaleza-SME, Fortaleza/CE, marconcio@gmail.com
} 
As crianças desenvolvem estratégias de compreensão do "eu e do outro" através da relação favorecida, também, pela vivência com os jogos. O espaço escolar é propício para que os jogos aconteçam como forma de favorecer a construção do conhecimento, como meio formativo do ensino e da aprendizagem.

A brincadeira e a ludicidade são próprias da infância e o espaço escolar deve potencializar os jogos e as brincadeiras como estímulo significativo da formação integral do ser. Na sala de aula ou fora dela, o jogo aparece na resolução de conflitos, momentos de diversão e nas atividades ligadas ao conhecimento científico nas mais diversas áreas.

Propor situações didáticas na escola que demandem atividades com objetivos claros, aprender através do jogo, representa o desejo do professor na busca da dinamização de suas aulas, entendendo o jogo como uma das atividades importantes para a educação. Segundo Murcia, "o jogo é um elemento transmissor e dinamizador de costumes e condutas sociais. Pode ser um elemento essencial para preparar de maneira integral os jovens para a vida" $(2005$, p.11).

Os jogos matemáticos trazem nessa área da ciência uma oportunidade de desmistificar o conhecimento e a construção de conceitos matemáticos, como um saber que ao longo do tempo foi reforçado pela dificuldade de transmissão e de assimilação dos conteúdos.

Diante do exposto, as questões norteadoras dessa pesquisa foram: a) Quais as dificuldades encontradas no trabalho pedagógico da subtração?, b) Que jogos matemáticos os professores utilizam para trabalhar subtração?, e c) Que contribuições para melhoria do processo de ensino aprendizagem da subtração os professores atribuem ao uso de jogos matemáticos em suas aulas?

Entender, através da visão do professor, o que significa a didática nos jogos matemáticos e, investigar que contribuições relevantes traz essa proposta para ambos os sujeitos que ensinam, e aprendem é de grande relevância na atualidade.

Nosso objetivo geral, nessa pesquisa, foi investigar que contribuições os professores atribuem aos jogos matemáticos como recurso didático para superação de dificuldades no trabalho pedagógico da subtração. Mais especificamente buscamos: a) Analisar que dificuldades são apresentadas pelos professores no trabalho da subtração, b) Relacionar que jogos matemáticos são utilizados pelos professores como recurso didático para o ensino da subtração e c) Analisar que contribuições para melhoria do processo de ensino e aprendizagem os 
professores atribuem ao uso de jogos matemáticos em suas aulas.

O papel do docente deve ser compreendido através da leitura que infere sobre a Matemática, como área de conhecimento em pauta e os jogos matemáticos como possibilidade de trabalho em sala de aula, levando em consideração os saberes construídos ao longo do processo e a relevância das descobertas.

\section{Percurso metodológico}

A pesquisa desenvolvida foi realizada tendo uma abordagem com predominância qualitativa, onde mantivemos contato direto com os sujeitos, ambientes e situações que fazem parte da investigação, pois "as ações podem ser melhor compreendidas quando são observadas no seu ambiente habitual de ocorrência. Os locais têm de ser entendidos no contexto da história das instituições a que pertencem" (BOGDAN; BIKLEN, 2010, p.48).

Escolhemos como método a pesquisa exploratória que “objetiva dar uma explicação geral sobre determinado fato, através da delimitação do estudo, levantamento bibliográfico, leitura e análise de documentos" (OLIVEIRA, 2008, p.65).

O local de pesquisa foi uma escola particular da cidade de Fortaleza, situada em um bairro de classe média alta, sendo os sujeitos três professoras do 4 을 ano do Ensino Fundamental. As professoras investigadas tinham entre 30 e 50 anos de idade, sendo formadas em Pedagogia, estando todas com mais de 15 anos de trabalho no exercício da docência no Ensino Fundamental. A pesquisa foi desenvolvida no segundo semestre de 2015.

Para coletar os dados de análise, trabalhamos com coleta de documentos e entrevistas, deixando margem para perguntas espontâneas que pudessem surgir. Durante a pesquisa realizamos um apanhado de documentos como o plano anual e o de aulas da etapa e entrevistas, pois esta "pode oferecer elementos para corroborar evidências coletadas por outras fontes, possibilitando triangulações e consequente aumento do grau de confiabilidade do estudo" (MARTINS, 2008, p.27).

As evidências foram analisadas seguindo a adequação ao padrão que "compara um padrão fundamentalmente empírico com outro de base prognóstica (ou com várias outras previsões alternativas)" (TROCHIM, 1989, apud YIN, 2001, p.136). 


\section{Fundamentando e discutindo os resultados}

O professor deve buscar constantemente refletir sobre a sua formação e a prática, como ponto de partida para o processo de ensino e de aprendizagem. Como sujeito que ensina e aprende deve buscar investir em sua formação e enxergar como maior fonte de conhecimento o olhar sobre sua prática docente cotidiana.

O jogo dentro de uma perspectiva construtiva, como instrumento que colabora para despertar em crianças, jovens e adultos, interesse pela descoberta do conhecer, se apropriando do universo científico, pode ser um elemento propulsor da construção do conhecimento matemático de forma integrativa, socializadora e formativa.

Abrir a mente para a proposta de jogos nesta área de conhecimento e construir conceitos a partir dos estímulos aos alunos, dúvidas e certezas colocadas por eles, é também investir na própria aprendizagem como processo contínuo e necessário à prática educativa.

É preciso deixar que os alunos falem, é preciso ter uma escuta apurada, aguçada no sentido investigativo. Certamente, muitas propostas irão nascer desses momentos. Tudo é importante, tanto a fala, quanto o silêncio dos alunos. O professor que se permite buscar o conhecimento matemático através do lúdico traz consigo possibilidades variadas de ensino e de aprendizagem.

Segundo Kamii,

Quando ensinamos número e aritmética como se nós adultos, fôssemos a única fonte válida de retroalimentação, sem querer ensinamos também que a verdade só pode sair de nós. Então a criança aprende a ler no rosto do professor sinais de aprovação ou desaprovação. Tal instrução reforça a heteronomia da criança e resulta numa aprendizagem que se conforma com a autoridade do adulto. Não é dessa forma que as crianças desenvolverão o conhecimento do número.

A autonomia, ou a confiança em sua habilidade matemática (2008, p.62).

A prática dos jogos deve ser observada como possibilidade de trabalho pedagógico e construção de conhecimentos matemáticos. No entanto, o professor precisa ter cuidado com o que vai propor, deve conhecer bem seu grupo de alunos, faixa etária, o que os alunos querem e o que está dentro de suas possibilidades. 
Cada jogo trabalhado poderá revelar conhecimentos ou inquietações oriundos da falta de entendimento dos alunos acerca de conceitos e conteúdos matemáticos. A observação é tão importante como o momento da construção do jogo. Todos os aspectos envolvidos, social, cognitivo e emocional podem se revelar através desta atividade.

No desenvolver da pesquisa, sobre quais as dificuldades encontradas no trabalho com a subtração, as professoras responderam:

O que percebo como maior dificuldade é a não consolidação das regularidades do sistema de numeração, a relação entre as ordens: unidade, dezena, centena, unidade de milhar. Como também a conservação do número, principalmente $(600-185)$ em que aprece várias trocas com zeros. A dificuldade de perceber que esses zeros compõem um número maior (PROFESSORA A).

Ideias básicas dos 20 e 30 anos. Quando uma operação exige uma ou mais trocas. A compreensão do nome dos termos. Quando ele compreende que o minuendo é o maior termo, fica mais fácil. Valor posicional do número. Ex.: 185-28 ele arma assim,

$$
\begin{array}{r}
185 \\
-28 \\
\hline 105
\end{array}
$$

com isso a operação vai dá errada. Conservação do número. Quando a troca vem da dezena para centena. Quando ele tem que fazer a troca da centena para dezena e para a unidade (PROFESSORA B).

Organização do algoritmo. Percepção de que a maior quantidade deve ser a $1^{\text {a }}$ a ser colocada no cálculo. Compreensão do valor inserido nas trocas. Uma ordem ao ser desagrupada está sendo transformada na ordem anterior a ela. Portanto, deixa de ser 1 e passa a ser 10 . Ordem varia na quantidade maior (ocupada pelo zero): não realizam a troca. Colocam a quantidade do subtraendo. Quantidade diferente de zero apenas na maior grandeza: realização de trocas sucessivas. Agilidade no cálculo (PROFESSORA C).

As dificuldades relatadas pelas professoras $A, B$ e $C$, são pertinentes quando os alunos não fazem uso de uma construção de conceitos básicos, que é iniciada nas séries anteriores ou até mesmo é nascida na Educação Infantil que, consequentemente, desencadeia no Ensino Fundamental e permanece como fator que dificulta a compreensão do que seja a subtração. É importante utilizar diferentes recursos para trazer a compreensão deste conteúdo e do grau de dificuldade que vai aparecendo de forma crescente. 
Segundo Vergnaud,

A subtração corresponde a operações tão naturais quanto a adição (tirar, perder, sair...). Isso não significa, no entanto, que a regra operatória da subtração seja tão fácil quanto a da adição, mesmo quando se procede, para as reservas, de uma forma exatamente inversa a da adição: para ter unidades suficientes, desfaz-se de um grupo (ou se quebra uma barra do material de bases múltiplas) etc. A hierarquia das dificuldades é bastante conhecida: ausência de reserva, reserva em uma coluna isolada, reserva em duas colunas sucessivas, reserva com zero na coluna da reserva etc. (2014, p.179-180).

Para o professor é importante entender que a busca pelo processo de ensino e de aprendizagem já é uma prática que se difunde nas salas de aula e que o jogo matemático pode ser mais um recurso didático. Os livros didáticos já trazem os jogos como abordagem em alguns capítulos, como parte do bloco de atividades ou recursos extras que se integram ao material. Dessa forma, pode-se inferir que esse recurso é visto como importante nesse processo de construção do conhecimento.

Os jogos organizam-se em diferentes modalidades para atender às necessidades dos alunos. Podem ser realizados individualmente, em dupla, trio, grupos maiores, porém, o mais importante a ser entendido é que implicam no conhecimento que o professor tem sobre a Matemática, os conteúdos e a didática, para serem obtidos resultados significativos. Na proposta do jogo o professor deve escolher um espaço privilegiado à proposta e tempo adequado para a sua realização, com segurança e tranquilidade. O professor que escolhe trabalhar com jogo deve ter mais que o conhecimento da disciplina, ou seja, sensibilidade, postura flexível para compreender o que o jogo revela através do momento do jogar e o que o jogador traz como elucidativo diante a brincadeira proposta.

Segundo Almeida (2006) citado em lavorski e Venditti Junior, (2008, n/p),

A palavra ludicidade tem sua origem na palavra latina 'ludus' que quer dizer 'jogo'. Se achasse confinada a sua origem, o termo lúdico estaria se referindo apenas ao jogo, ao brincar, ao movimento espontâneo, mas passou a ser reconhecido como traço essencialmente psicofisiológico, ou seja, uma necessidade básica da personalidade do corpo e da mente no comportamento humano, as implicações das necessidades lúdicas extrapolaram as demarcações do brincar espontâneo de modo que a definição deixou de ser o simples sinônimo de jogo. O lúdico faz parte das atividades essenciais da dinâmica humana, trabalhando com a cultura corporal, movimento e expressão. 
De acordo com a definição anterior, o lúdico se confirma como elemento básico do ser humano, que denota movimento, corporeidade, necessidade de expressão. Aspectos estes, observados em crianças e adultos. Nessa perspectiva, a ludicidade se entrelaça ao movimento do jogo e nos fortalece para o entendimento de que o jogo, a brincadeira, a ludicidade, estão presentes nas atividades diárias das crianças e podem ser aproveitadas no processo educativo, no ensino e na aprendizagem. Aprendizagem de forma espontânea para o aluno, que poderá aprender através do jogo, do lúdico, das representações.

Sobre a utilização de jogos matemáticos para o trabalho com subtração as professoras disseram que,

Diante dessas necessidades trabalhamos jogos que sistematizam essas regularidades do sistema de numeração como: composição, decomposição, trocas e representação. Para depois abordar as trocas de subtração no algoritmo.

- $\quad$ Utilizo o jogo das cores: (Tabuleiro colorido onde cada cor representa uma ordem para compor números até a 4ạ ordem).

- Jogo das fichas: fichas representativas com cores diferentes e dados para compor e decompor o número).

- Termo desconhecido da subtração: tabuleiro ou ficha onde as crianças identificarão o algarismo que está faltando para completar o quadro algoritmo da subtração (PROFESSORA A).

O jogo dos algarismos desconhecidos:

- Uso do material dourado.

- $\quad$ Operação com fichas de 1, 10,100,1000.

- Trabalhando com o ábaco.

- $\quad$ O algoritmo pela decomposição.

- Jogo com dados (formar número e fazer diferença entre ele).

- Jogo dos pratos e das cores (PROFESSORA B).

- Jogo do tabuleiro - é construído um tabuleiro onde estão os resultados de várias subtrações e várias cartelas com subtrações que eles vão retirando no momento da sua vez. Ganha quem tiver marcado mais respostas.

- Jogo da roleta da subtração - constrói-se um círculo onde são colocados números de acordo com o critério do professor.

- $\quad$ Bingo da subtração - cartelas com várias quantidades como a de um bingo comum. Várias situações que são lidas pelo professor. Os alunos marcam as cartelas com a quantidade que está relacionada aos problemas. Ganha quem preencher uma coluna ou uma linha de cartela.

- Jogo do passa e repassa - a sala é dividida em dois grupos. É escolhido aluno de um lado e de outro. O professor dita uma subtração e o aluno que responder certo ganha um ponto para o seu grupo. Ganha quem fizer mais pontos (PROFESSORA C). 
A variedade de jogos utilizados pelas professoras $A, B$ e $C$ demonstra que percebem a importância destes recursos como aporte para a compreensão do conteúdo em pauta. A relação do trabalho com o material, cores, símbolos e estratégias dinamiza a prática e traz a ludicidade como forma efetiva e significativa nos momentos de construção do conhecimento.

Para a realização desse trabalho todas as estratégias propostas foram pensadas com base em um planejamento prévio, utilizando fontes de consulta como o planejamento anual, livros, periódicos e Projeto Político-Pedagógico da escola.

Segundo Murcia,

Centrando a atenção na análise entre o jogo e planejamento curricular, verificase que o jogo parte de uma matéria concreta ao observar que contribui para o sucesso dos objetivos e etapa e área, proporcionando conteúdos globalizadores, integradores, específicos e relacionados com os três blocos do currículo (conceitual, de procedimentos e atitudes); pela estrutura de suas atividades e tarefas e por suas especiais características lúdicas, possui recursos metodológicos convergentes com as orientações pensadas finalmente dispõe dos recursos para obter informação sobre os critérios de avaliação assinalados (2005, p.96).

O professor deve criar espaços e estratégias de aprendizagem oportunizando o aluno a criar confiança no processo, olhar o jogo como instrumento que traz afeto, alegria, superação de limites, oportunidade de interação com o outro, conhecimento e prazer.

O aprendiz deve sentir-se encorajado a superar limites, o jogo pode proporcionar esse encorajamento, pois, ao brincar, a criança muitas vezes se esquece das suas dificuldades e não tem o medo de errar. O erro, nesse momento, poderá servir como ponte para o caminho do acerto.

Conforme Almeida,

Os jogos, os brinquedos e brincadeiras existem há muito tempo. Não sabemos quem os criou ou inventou, apenas que eles foram transmitidos através da comunicação oral, são universais e passados de geração a geração. Estes jogos estiveram presentes em vários períodos da história do homem e na sociedade. Tal fato se perpetuou por meio de sua tradicionalidade, da sua oralidade e da sua universalidade, sempre estando presente na cultura do povo $(2009, \mathrm{p} .15)$.

A proposta de trabalhar com os jogos matemáticos exige do professor, além de sua formação, planejamento e didática, o prévio conhecimento do jogo a ser trabalhado, a pesquisa 
como tarefa contínua e a constância na formação continuada.

Ludicidade e aprendizagem devem caminhar juntas, de forma alinhada e coerente. A aprendizagem só pode acontecer quando os sujeitos do processo, aluno e professor, sabem falar de suas experiências, das suas dificuldades, do ponto de partida com vistas ao caminho a percorrer. O aluno deve sentir-se encorajado e confiante no professor e o professor seguro de sua teoria para aplicação da prática. Se o professor consegue ter uma visão crítica e aberta sobre a possibilidade de trabalho com a ludicidade através do jogo, o interesse renova-se de forma mútua.

O olhar dos sujeitos que ensinam e aprendem, vai se transformando a partir da mudança de paradigmas. É preciso romper com o que não produz crescimento, olhar a realidade e experimentar a mudança. Trazer a aprendizagem do passado e confrontar com a que se apresenta.

A ciência, fonte inesgotável de toda a busca por entendimento do que permeia a vida e suas relações com o conhecimento, desvenda mitos e configura a realidade.

A Matemática, historicamente, foi considerada uma das matérias mais difíceis e se iniciava nas escolas juntamente com a leitura e a escrita (ARANÃO, 1996). Essa dificuldade foi permanecendo ao longo do tempo e a desconstrução desse estigma merece ser refletida a partir das propostas de intervenção que são realizadas nas práticas educativas. A Matemática precisa ser encarada como conhecimento necessário das situações simples cotidianas e que nasce das necessidades humanas, desde as civilizações mais remotas.

Segundo Lorenzato "se o professor orientar seus alunos para que observem situações práticas, estes poderão concluir que as aplicações revelam como a Matemática está forte e cotidianamente relacionada com o nosso viver" $(2010$, p.56).

A aprendizagem e o ensino partem da concepção de educação que sustenta a prática dos professores. Se esta concepção tem uma relação direta com a aprendizagem de forma dinâmica e se o professor compreende esse processo com a interação de objetos e de outros sujeitos, o jogo passa a ter um significado importante no desenvolvimento da criança, enquanto atividade que proporciona o ensino e a aprendizagem (ZUNINO, 1995).

O jogo, como atividade de construção da autonomia do sujeito que aprende, permite fazer relações com os saberes construídos dia a dia individualmente e nas relações coletivas, 
resignificando conhecimentos adquiridos, demonstrando a flexibilidade do pensamento. As atividades pensadas para grupos e com os grupos podem levar o professor a compreender que caminhos percorrer nas suas produções didáticas para os alunos, qual o sentido das dinâmicas propostas, permitindo reafirmar a sua intencionalidade pedagógica.

Concordamos com Kamii, quando diz que,

Corrigir e ser corrigido pelos colegas nos jogos em grupo é muito melhor do que aquilo que porventura possa ser aprendido através das páginas de exercício. Ao preencherem páginas dos cadernos de exercícios as crianças fazem apenas seu próprio trabalho e não examinam a maneira de pensar das outras. Além disso, quando terminam sua folha elas a devolvem a professora para que esta julgue a correção de cada resposta. Tal dependência da autoridade do adulto é ruim para o desenvolvimento tanto da autonomia quanto da lógica da criança. Nos jogos em grupo as crianças estão mentalmente muito mais ativas e críticas e aprendem a depender delas mesmas para saber se seu raciocínio está correto ou não $(2008$, p.63).

Desta forma, vale buscar o entendimento das práticas educativas e as contribuições dos jogos matemáticos no processo de ensino e de aprendizagem, compreendendo que o conhecimento se dá das mais variadas formas em inúmeras situações. O ensino e a aprendizagem não acontecem de fora para dentro, são construídos nas vivências, nas ações do sujeito com o meio que interage.

Segundo as professoras, os jogos contribuem na superação das dificuldades do trabalho da subtração, pois,

Percebo que a partir da estruturação dessas regularidades, as crianças começam a estabelecer relações com diferentes números, comparar diferentes números, estabelecer quem é maior ou menor, como também as noções de arredondamento, quanto falta para chegar à unidade de milhar exata, por exemplo. Então a partir desse ponto, investimentos em situações problemas com mais complexidade (PROFESSORA A).

A alegria em perceber na prática a troca, principalmente, com alunos na fase do operatório concreto. $O$ jogo possibilita a compreensão da troca e a capacidade de utilizar corretamente. Faz com que o aluno perceba as trocas e partilhe com o outro o seu saber. No algoritmo pela decomposição, o aluno percebe a história do "Pedir emprestado" (emprego errado) que no caso seria transformar a dezena em unidade. O professor explica o porquê dos conteúdos, os conceitos, os termos. 
Ex.: Q.V.L (Quadro de Valor de Lugar). Ideias de subtração (PROFESSORA B).

Estimula na agilidade do cálculo mental, realização da atividade de forma prazerosa, busca por resposta correta. Esses pontos citados acima propiciam a eles a busca por saber como fazer para chegarem à resposta sem errar, o que permite a organização dos conceitos e do processo subtrativo, facilitando o algoritmo convencional (PROFESSORA C).

A superação das dificuldades no entendimento da subtração teve um desfecho positivo com relação ao processo de compreensão do jogo como ferramenta de ensino e aprendizagem. A forma de explicar e refletir o conteúdo não mais se configura única e solitária através do trabalho expositivo. Os jogos juntamente com os livros e as explicações, formam um conjunto importante e necessário à prática educativa. Desejo, motivação, curiosidade, partilha com os colegas e professores, das dificuldades e descobertas, foram propulsores para a aprendizagem na construção do conhecimento matemático.

\section{Considerações finais}

As contribuições da pesquisa foram de suma importância para a compreensão de como o docente vê e utiliza o jogo dentro do processo de ensino e de aprendizagem no trabalho com a subtração.

As possibilidades com os jogos, demonstradas dentro da pesquisa, foram inúmeras, desde a construção de conceitos a conhecimentos anteriores ao entendimento propriamente dito da subtração. Essa relação vai desde a possibilidade do jogo como estratégia para o conhecimento matemático à prática e disponibilidade do professor, visando à possibilidade de um trabalho fundamentado e integrativo entre professores e alunos.

A partir das informações coletadas, observamos professores preocupados com 0 processo de ensino e aprendizagem e como se constrói e sistematiza o conhecimento.

O jogo trouxe possibilidade de mudanças e da relação das crianças com a apreensão do conhecimento do conteúdo matemático, subtração. O jogo foi revelador, promotor de uma relação saudável e prazerosa entre professor e aluno, aluno e aluno. O olhar atento e observador das professoras retrata que trabalhar com jogos requer flexibilidade, tempo, dedicação, leitura etc.

No entanto, vale ressaltar que ainda se faz pertinente aprofundar pesquisas que possam 
investigar como o professor relaciona o lúdico, o jogo e o brincar, para além de uma possibilidade de trabalho para a construção de saberes conceituais.

Não conseguimos observar, na pesquisa, o lúdico como parte inerente à infância. A concepção de infância precisa ser mais bem difundida e estudada como campo de conhecimento essencial para a prática de professores nas séries iniciais.

\section{Referências}

ALMEIDA, M. T. P. Brincando com palitos e adivinhações. Petrópolis: Vozes, 2009.

ARANÃO, I. V. D. A matemática através de brincadeiras e jogos. Campinas-SP: Papirus, 1996.

BOGDAN, R.; BIKLEN, S. Investigação qualitativa em educação: uma introdução à teoria e aos métodos. Porto: Porto Editora, 2010.

IAVORSKI, J.; VENDITTI JUNIOR, R. A ludicidade no desenvolvimento e aprendizado da criança na escola: reflexões sobre a Educação Física, jogo e inteligências múltiplas. 2008, s/p. Disponível em: http://www.efdeportes.com/efd119/a-ludicidade-no-desenvolvimento-eaprendizado-da-crianca-na-escola.htm. Acesso em: 26 abr. 2015.

KAMII, C. A criança e o número: implicações educacionais da teoria de Piaget para a atuação com escolares de 4 a 6 anos; Trad. Regina A. de Assis. 36.ed., Campinas: Papirus, 2008.Disponível em: http://books.google.com.br. Acesso em: 03 out. 2015.

LORENZATO, S. Para aprender matemática. Campinas-SP: Autores Associados, 2010.

MARTINS, G. A. Estudo de caso: uma estratégia de pesquisa. São Paulo: Atlas, 2008.

MURCIA, J. A. M. Aprendizagem através do jogo. Porto Alegre: Artmed, 2005.

OLIVEIRA, M. M. Como fazer pesquisa qualitativa. 2.ed., Petrópolis: Vozes, 2008.

VERGNAUD, G. A criança, a matemática e a realidade: problemas do ensino da matemática na escola elementar. Trad. Maria Lucia F. Mouro. Curitiba: Editora UFPR, 2014.

ZUNINO, D. L. A matemática na escola: aqui e agora. Porto Alegre: Artes Médicas, 1995.

YIN, R. K. Estudo de caso: planejamento e método. Porto Alegre: Bookman, 2001.

Recebido em janeiro 2020.

Aprovado em junho 2020.

Periódico Horizontes - USF - Itatiba, SP - Brasil - e020052 